Research Article

\title{
Optimization of Wireless Communication Coverage in Underground Tunnels Based on Zone Division
}

\author{
Yu Huo $\mathbb{D},{ }^{1}$ Qingsong Hu $\mathbb{D}^{1},{ }^{1}$ Yanjing Sun $\mathbb{D}^{1},{ }^{1,2}$ Xiwang Guo $\mathbb{D}^{\circ},{ }^{3}$ Liang Qi $\mathbb{D}^{,},{ }^{4}$ \\ Xiaohu Zhao $\mathbb{D}^{1}{ }^{1}$ and Enjie Ding $\mathbb{D}^{1}$ \\ ${ }^{1}$ National and Local Joint Engineering Laboratory of Internet Applied Technology on Mine, \\ School of Information and Control Engineering, China University of Mining and Technology, Xuzhou 221116, China \\ ${ }^{2}$ Xuzhou Engineering Research Center of Intelligent Industry Safety and Emergency Collaboration, Xuzhou 221116, China \\ ${ }^{3}$ Computer and Communication Engineering College, Liaoning Shihua University, Fushun 113001, China \\ ${ }^{4}$ College of Computer Science and Engineering, Shandong University of Science and Technology, Qingdao 266590, China
}

Correspondence should be addressed to Qingsong Hu; hqsong722@163.com

Received 24 September 2020; Revised 28 October 2020; Accepted 9 November 2020; Published 23 November 2020

Academic Editor: Mauro Parise

Copyright (c) 2020 Yu Huo et al. This is an open access article distributed under the Creative Commons Attribution License, which permits unrestricted use, distribution, and reproduction in any medium, provided the original work is properly cited.

\begin{abstract}
In order to reduce the path loss of the wireless communication signal in the underground tunnel, a scheme for configuring the antenna polarization of wireless systems based on a zone-division method is proposed. A multimodal method is used to estimate the effect of antenna polarization on the wireless propagation. When the optimal polarization of the antenna leading to low path loss is different in the zones near and far from the transmitting antenna, a dividing point is used to separate the zones. Experiments are conducted in an underground mine. It shows that the results by the multimodal method are consistent with the real data. Compared with the existing coverage schemes, the proposed scheme can obtain better coverage. Meanwhile, zone division has an important influence on the optimized performance of the wireless coverage. The zones divided based on Fresnel zone clearance and system identification are too small or too large, which result in incorrect polarization switching and high path loss.
\end{abstract}

\section{Introduction}

Mining is very important in modern life by supporting mankind with energy and various mineral resources. A large proportion of mining operations take place underground. The operating environment is very dangerous because underground hazards (e.g., roof falls and toxic gases) occur from time to time [1-3]. With the development of smart technologies, wireless communication is used at every stage of mining operations, such as personnel positioning, environmental monitoring, remote operation, and emergency rescue [4-8]. With the aid of wireless communication, working safety, productivity, and emergency response efficiency in underground mines can be greatly improved. The effectiveness and reliability of coverage play a significant role in the quality of wireless communications. In underground mines, radio waves do not propagate well [1-3]. Wireless devices are powered by batteries with limited capacity.
Therefore, optimizing the coverage of energy-constrained devices in underground mines is a challenging and significant task.

In [9], the attenuation of the signal power is reduced by optimizing the position of the antenna. In [10], radio wave coverage is optimized by using the spatial diversity and polarization diversity of the transceiver antennas. In [11], the optimal polarization is analysed by measuring radio propagation, so as to obtain the minimum attenuation of the signal power in the tunnel. In [12], it is reported that the optimal antenna polarization relies on the antenna position. The coverage schemes studied in [9-12] usually focus on the deployment optimization of wireless devices, so the signal power can be improved only when the antenna is in a certain position. In addition, the authors in [9-12] use the same antenna polarization to communicate in the whole tunnel. However, it is found that the effect of antenna polarization on signal propagation is different in the zones near and far 
from the transmitter [13]. In underground mines and tunnels, only the horizontally polarized antenna can achieve low path loss when the electromagnetic signal is propagated in the zone far from the transmitter [13-15]. When the wireless signal is propagated in the zone near the transmitter, the vertically polarized antenna can also obtain low path loss $[12,13]$. In underground mines, many wireless users are mobile, such as miners, vehicles, and some mining machines. Hence, in order to reduce the power loss of the signal for communication, it is necessary to distinguish the different propagation regions of the wireless system and configure different optimal antenna polarization as the user moves. This paper expands the work in [13]. It employs region division and polarization switching to realize dynamic coverage optimization of wireless systems at any position in the tunnel.

In studies [16-20], a dividing point is used to separate the propagation regions near and far from the transmitting antenna. This point is determined by the first Fresnel zone clearance. In $[21,22]$, the dividing point of the regions is determined by system identification. It has been proved to be reasonable for path loss modeling and prediction [16-22], whereas existing methods of zone division do not take into account the axial variation of the optimal polarization. Whether the antenna polarization configuration and coverage optimization based on the existing zone-division methods are reasonable has not been verified.

The major contributions of this paper are as follows:

(1) A multimodal method is proposed to quickly estimate the axial variation of the optimal antenna polarization and the dividing point of the propagation zones in the tunnel. The method depends on the solution of the propagation equation.

(2) Zone division and polarization switching are applied to dynamic coverage optimization of the wireless system for communication in underground mines and tunnels. The effectiveness and feasibility of the coverage optimization are validated by experiments in real mines.

In addition, from empirical studies, it shows the difference in zone division between our proposed method and existing methods. The significant effect of zone division on the performance of coverage optimization is also shown.

The rest of this paper is organized as follows. The related work is introduced in Section 2. The optimization strategy for coverage is described in Section 3. It also presents the proposed zone-division method. Sections 4 and 5 conduct numerical experiments for zone division and coverage optimization examples and analyse experimental results. Section 6 concludes this work and discusses the future works.

\section{Related Work}

Radio field coverage in underground tunnels can be improved by the positions, polarization, and radiation patterns of the antennas [1]. Table 1 summarizes some existing efforts to optimize wireless communication coverage in underground tunnels.

Li and Wang [9] use a modal method to discuss the effects of the antenna on the field coverage in tunnels. The results indicate that the attenuation of the signal power can be reduced by narrow beam width and proper location of the transmitting antenna. However, the optimal configuration of antenna parameters is not given in this study. Besides, $\mathrm{Li}$ and Wang [9] suggest that the deep fading of radio waves in a tunnel can be suppressed by the spatial diversity of the transceiver antennas. This work is extended in [10]. Two antennas are used to realize spatial diversity. The locations of the antennas are determined by finding the smallest correlation coefficient. By combining polarization with diversity, the field intensity and uniformity can be further improved.

Zhou et al. [11] discuss the effect of antenna polarization on radio propagation by extensive measurements in mines and tunnels. Results show that horizontal polarization gives the minimum attenuation in the tunnel which has a larger width than its height.

Bashir [12] reports that the optimal antenna polarization for ultrawideband (UWB) propagation channel relies on the antenna position. Analysis is based on channel measurements. The results show that the horizontally polarized antenna can obtain low average path loss when it is mounted on the ceiling, whereas the vertically polarized antenna can obtain low average path loss when it is mounted on a side wall of the tunnel.

Based on multimode theory, Huo et al. [13] find that the results reported in [12] are valid when the receiver is located near the transmitter. However, when the receiver is located far from the transmitter, only the horizontally polarized antenna can achieve low path loss. The optimal mounting location of the antenna is the center of the ceiling and the center of the side wall. Besides, both horizontally and vertically polarized antennas have the weakest signal strength at the corner of the tunnel cross-section.

On one hand, existing coverage optimization studies [9-13] mainly focus on the deployment of wireless devices. The power of wireless signal can be improved only when the antenna is in a certain position. However, it is also necessary to solve the coverage optimization problem of the wireless devices in nonoptimal locations because wireless devices may not always be installed in the theoretically optimal locations in practice. The real deployment of wireless nodes and sensors should also consider the location of monitored objects (e.g., hazard sources), deployment of mining infrastructure, influence of industrial electromagnetic noise generated by mining machine, and so on. On the other hand, the coverage schemes in [9-12] usually use the same antenna polarization to communicate in the whole tunnel. In underground mines, some wireless communication devices are carried by miners and some mining machines. Their locations change dynamically as miners and mining machines move. In this nonstatic scenario, it is essential to develop a dynamic configuration strategy in which the polarization changes with the user's movement. The reason is that the optimal antenna polarization for radio propagation is different in the zones near and far from the transmitter [13]. 
TABLE 1: Examples of wireless coverage optimization scheme in underground tunnels.

\begin{tabular}{|c|c|c|c|}
\hline $\begin{array}{l}\text { Research } \\
\text { group }\end{array}$ & Optimization scheme & Characteristics & Limitations \\
\hline $\begin{array}{l}\mathrm{Li} \text { and } \\
\text { Wang [9] }\end{array}$ & $\begin{array}{l}\text { Antenna beam width and } \\
\text { antenna deployment }\end{array}$ & $\begin{array}{l}\text { (1) Use antennas with narrow beam width } \\
\text { (2) Deploy antennas on proper locations }\end{array}$ & $\begin{array}{l}\text { Optimal configuration of antenna parameters } \\
\text { is not given } \\
\text { (1) Optimization is limited by antenna }\end{array}$ \\
\hline $\begin{array}{l}\text { Zhao et al. } \\
{[10]}\end{array}$ & Antenna diversity & $\begin{array}{l}\text { Use spatial and polarization diversities of two } \\
\text { antennas }\end{array}$ & $\begin{array}{c}\text { locations } \\
\text { (2) Scheme cannot be adjusted dynamically as } \\
\text { the user moves }\end{array}$ \\
\hline $\begin{array}{l}\text { Zhou et al. } \\
{[11]}\end{array}$ & Antenna polarization & $\begin{array}{l}\text { Use the horizontally polarized antenna to } \\
\text { communicate }\end{array}$ & $\begin{array}{l}\text { (1) Scheme cannot be adjusted dynamically as } \\
\text { the user moves } \\
\text { (2) Optimization is restricted to the case } \\
\text { where the receiver is in the far-field region of } \\
\text { the transmitter }\end{array}$ \\
\hline Bashir [12] & Antenna deployment & $\begin{array}{l}\text { Consider the interaction of the effects of antenna } \\
\text { polarization and location on field propagation }\end{array}$ & $\begin{array}{l}\text { (1) Optimization is limited by antenna } \\
\text { locations } \\
\text { (2) Scheme cannot be adjusted dynamically as } \\
\text { the user moves } \\
\text { (3) Optimization is restricted to the case } \\
\text { where the receiver is in the near-field region of } \\
\text { the transmitter }\end{array}$ \\
\hline $\begin{array}{l}\text { Huo et al. } \\
{[13]}\end{array}$ & Antenna deployment & $\begin{array}{l}\text { Consider the different effects of antenna } \\
\text { polarization on field propagation in the near- } \\
\text { field and far-field zones }\end{array}$ & $\begin{array}{l}\text { (1) Optimization is limited by antenna } \\
\text { locations } \\
\text { (2) Scheme cannot be adjusted dynamically as } \\
\text { the user moves }\end{array}$ \\
\hline
\end{tabular}

Usually, zones for wireless propagation along the tunnel axis are separated by a dividing point [16-20]. On one side of the dividing point, the zone is close to the transmitter and is known as a near-field region. On the other side, the zone is far from the transmitter and is known as a far-field region. This point can be determined by the following two methods.

Method 1: most researchers use the Fresnel break point (FBP) to divide the near-field region and the far-field region [16-20]. The dividing point is given by

$$
z_{\mathrm{DV}}=\max \left(\frac{w^{2}}{\lambda}, \frac{h^{2}}{\lambda}\right)
$$

where $\lambda$ is the wavelength; $w$ and $h$ denote the width and the height of the rectangular tunnel, respectively. If the tunnel is nonrectangular, it can be equivalently surrogated by a rectangular tunnel [16-20], by using the method reported in $[23,24]$.

Method 2: system identification (SI) is used to estimate the parameters in the models that depict wireless propagation in the near-field region and the far-field region $[21,22]$. In the near-field region, the electromagnetic field has the lognormal distribution, and the path loss model is estimated by nonlinear optimization $[21,22]$. In the far-field region, the field exhibits an exponential fall-off, and the path loss model is estimated by linear optimization [21, 22]. The dividing point is the tangent point of the optimized nonlinear curve and the optimized linear curve of the field $[21,22]$.

Existing methods, which distinguish the near-field region and the far-field region of the source, are mainly based on the law of the field fading [16-22]. The difference in field power between horizontal polarization and vertical polarization is not captured by these methods.

In this paper, we focus on the dynamic coverage optimization of wireless devices at any position in the tunnel. Locations of the receiver and transmitter are the key parameters at every stage of the coverage procedure. User positioning and zone division are used to guide the polarization switching of the transceiver. The propagation zones are divided based on a multimodal method, which can quickly estimate the axial variation of the optimal antenna polarization in a tunnel.

\section{Methodology}

\subsection{Coverage Optimization for Wireless Communication}

3.1.1. Variation of Optimal Antenna Polarization for Wireless Communication. According to multimodal theory, the wireless propagation in the near-field region is dominated by multiple modes [18-21]. The modes that are significant for propagation and the optimal polarization with lower path loss are determined by the location of the antenna $[9,13]$. For example, $n(n=1,2$, and 3$)$ modes can be effectively excited and play significant roles in the propagation when the transceivers are close to the side walls of the tunnel [13]. Compared with the horizontally polarized excitation, these modes have lower path loss under the vertically polarized excitation [12,13], whereas $m(m=1,2$, and 3$)$ modes can be effectively excited when the transceivers are close to the ceiling of the tunnel [13]. Compared with the vertically polarized excitation, these modes have lower path loss under the horizontally polarized excitation [12, 13]. The horizontally polarized antenna is parallel to the floor. The 
vertically polarized antenna is parallel to the side walls of the tunnel.

In the far-field region, the field is dominated only by the fundamental mode [18-21]. The power attenuation of the fundamental mode is lower for horizontal polarization than vertical polarization [13-15]. Only horizontal polarization is optimal for signal propagation [13-15].

When the optimal polarization changes along the tunnel axis, we define the near-field region is the zone where the vertically polarized signal has a lower path loss. The far-field region is the zone where the horizontally polarized signal has a lower path loss. According to the propagation mechanism revealed by the multimodal theory [13], we consider the dividing point of both regions as the point where the highorder mode (the horizontally polarized and the vertically polarized wave) has greater power attenuation than the fundamental mode (the horizontally polarized wave).

3.1.2. Coverage Optimization. This work studies peer-topeer communication. The antenna position of the fixed wireless system is known. A Cartesian coordinate system is set with its origin located at the center of the tunnel. $x, y$, and $z$ axes denote the width, height, and length of the tunnel, respectively. The coordinate of the antenna of the fixed wireless system is expressed as $\left(x_{0}, y_{0}, 0\right)$.

The optimization process is as follows:

(1) Estimate the location of the user through positioning algorithms. $\left(x_{1}, y_{1}, z_{1}\right)$ denotes the coordinates of the antenna of the user.

(2) Estimate the variation of the optimal polarization with the axial distance in the tunnel.

(3) Divide the propagation zones:

If horizontal polarization has lower path loss in the propagation zones, there is no need to divide the zones. The fixed wireless system and the user use horizontally polarized antennas to send and receive signals;

Otherwise, the near-field region and the far-field region are divided by a dividing point. The location of the dividing point is indicated by its longitudinal coordinate $z_{\mathrm{DV}}$. The range of the near-field zone is from 0 to $z_{\mathrm{DV}}$.

(4) If the propagation zones are divided, configure the optimal polarization for the communication systems by comparing the position of the dividing point with the position of the user:

If $0 \leq z_{1} \leq z_{\mathrm{DV}}$, the user is in the near-field region. Wireless systems use vertically polarized antennas to send and receive signals $[12,13]$; if $z_{1}>z_{\mathrm{DV}}$, the user is in the far-field region. Wireless systems use horizontally polarized antennas to send and receive signals [13];

(5) If the communication does not end, return to step (1). Continue steps (1)-(4) until the communication end.
The procedure of coverage optimization for wireless communication in underground tunnels is shown in Figure 1. It can be used for most tunnels with their width being larger than their height. If the tunnel has a shorter width than its height, the polarization configuration for coverage optimization should be reversed [13]. If the width of the tunnel is equivalent to its height, there is no need to divide the communication cell to switch polarizations during the communication.

\subsection{Optimal Polarization Estimation and Zone Division}

3.2.1. Multimodal Method. The proposed zone-division method is a multimodal method (MM). Table 2 lists the symbols used in the paper.

The path loss of each mode $L_{m n}$ is given by $[13,25-28]$

$$
L_{m n}=\operatorname{Cop}_{m n}+\mathrm{MAF}_{m n}
$$

where $\operatorname{Cop}_{m n}$ is the loss of signal power at both the transmitter and receiver due to the inefficient coupling of the antennas to the $(m, n)$ mode and $\mathrm{MAF}_{m n}$ is the power loss of the $(m, n)$ mode as it propagates along the tunnel.

The restrictions of $m$ and $n$ in (2) are as follows [28]:

$$
\begin{gathered}
1<|m| \leq\left\lfloor\frac{2 w}{\lambda}\right\rfloor, \\
1<|n| \leq\left\lfloor\frac{2 h}{\lambda}\right\rfloor .
\end{gathered}
$$

The $(1,1)$ mode is the fundamental mode [28].

$\mathrm{Cop}_{m n}$ is given as

$$
\operatorname{Cop}_{m n}=-10 \log _{10}\left(\eta_{m n}^{T} \eta_{m n}^{R}\right),
$$

where $\eta_{m n}^{T}$ is the fraction of the transmitting antenna radiated power that is coupled to the $(m, n)$ mode; $\eta_{m n}^{R}$ is the coupling fraction for the power of the receiving antenna. The function of $\eta_{\mathrm{mn}}$ is reported in [13]. $\eta_{m n}^{T}$ and $\eta_{m n}^{R}$ change with antenna current density and antenna positions with respect to the tunnel cross-section, but change little with antenna polarization and communication distance [13].

$\mathrm{MAF}_{\mathrm{mn}}$ is a function of antenna polarization and the distance $[13,26,28]$ :

$$
\operatorname{MAF}_{m n}=-20 \log _{10}\left[e^{-\alpha_{m n} z}\right]=8.686 \alpha_{m n} z,
$$

where $\alpha_{m n}$ is the attenuation coefficient of the $(m, n)$ mode. $\alpha_{m n}$ can be calculated by functions reported in [28].

According to the definition of the dividing point in Section 3.2.1, we can get the following relationship when the waves travel to the dividing point:

$$
\begin{aligned}
& L_{m n}^{V} \geq L_{11}^{H}, \\
& L_{m n}^{H} \geq L_{11}^{H},
\end{aligned}
$$

where $L_{m n}^{V}$ and $L_{m n}^{H}$ are the path loss of the $(m, n)$ mode for vertical polarization and horizontal polarization, respectively. 


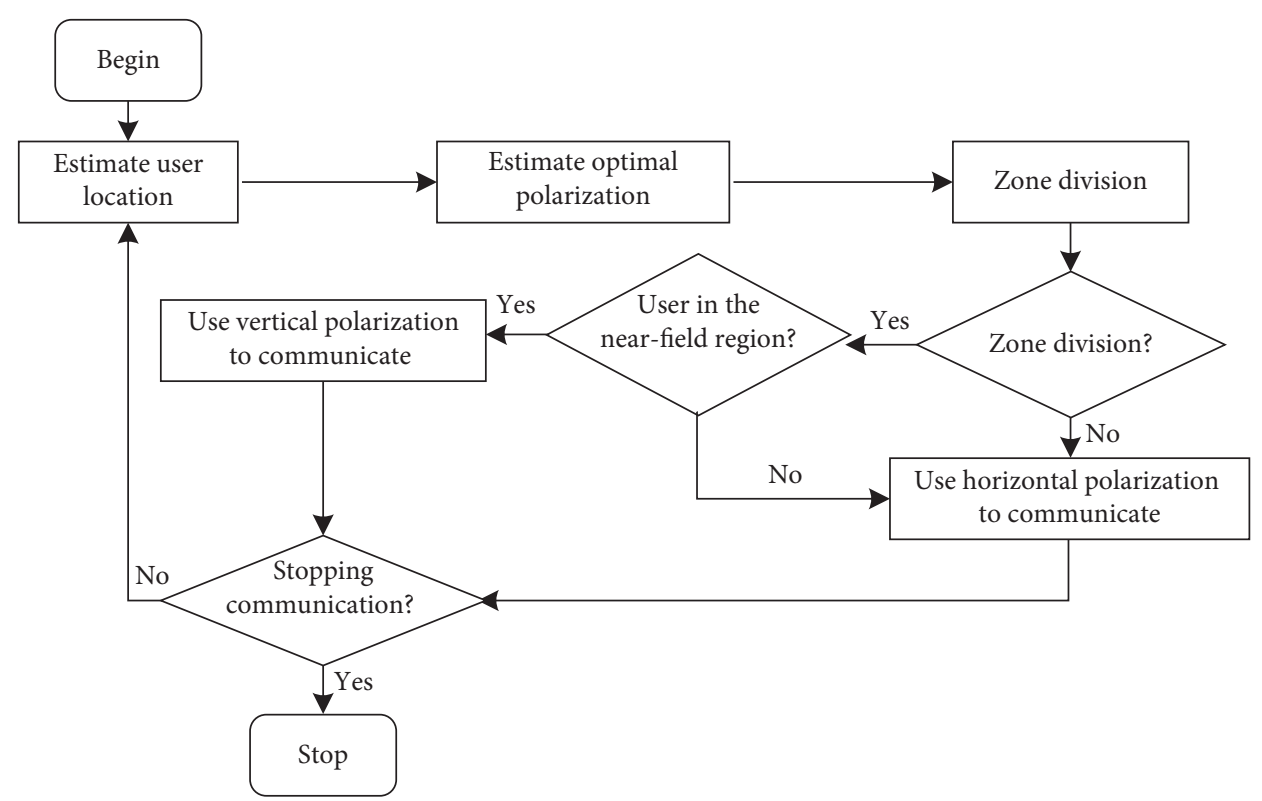

FIgURE 1: Procedure of coverage optimization for communication systems in underground tunnels.

TABLE 2: List of symbols used in this paper.

\begin{tabular}{|c|c|}
\hline Symbol & Quantity \\
\hline$w$ & Width of the rectangular tunnel \\
\hline$h$ & Height of the rectangular tunnel \\
\hline$\left(x_{0}, y_{0}, 0\right)$ & Coordinate of the antenna of the wireless device \\
\hline$\left(x_{1}, y_{1}, z_{1}\right)$ & Coordinate of the antenna of the user \\
\hline$m, n$ & Order of the waveguide mode \\
\hline$\lambda$ & Wavelength \\
\hline$L_{\mathrm{mn}}$ & Path loss of the $(m, n)$ mode \\
\hline Copmn $_{m}$ & Coupling loss of signal power at both the transmitting and receiving antennas \\
\hline $\mathrm{MAF}_{\mathrm{mn}}$ & Power loss of the $(m, n)$ mode as it propagates along the tunnel \\
\hline$\eta_{m n}^{T}$ & Coupling fraction of the transmitting antenna power along the $(m, n)$ mode \\
\hline$\eta_{m n}^{R}$ & Coupling fraction of the receiving antenna power along the $(m, n)$ mode \\
\hline$\alpha_{m n}$ & Attenuation coefficient of the $(m, n)$ mode \\
\hline$z_{\mathrm{DV}}$ & Longitudinal coordinate of the location of the dividing point \\
\hline$Z_{m n}^{V}$ & $\begin{array}{c}\text { Boundary of the zone where the attenuation of the vertically polarized }(m, n) \text { mode is larger than that of the horizontally } \\
\text { polarized }(1,1) \text { mode }\end{array}$ \\
\hline$Z_{m n}^{H}$ & $\begin{array}{c}\text { Boundary of the zone where the attenuation of the horizontally polarized }(m, n) \text { mode is larger than that of the horizontally } \\
\text { polarized }(1,1) \text { mode }\end{array}$ \\
\hline$P_{\mathrm{v}}$ & Vertically polarized field power \\
\hline$P_{\mathrm{h}}$ & Horizontally polarized field power \\
\hline$\Delta P$ & Power difference between vertical polarization and horizontal polarization \\
\hline$\overline{\Delta P}$ & Mean value of $\Delta P$ per unit length \\
\hline$p$ & Pseudoperiod of the field variation \\
\hline$z_{0.5}$ & Longitudinal coordinate of the location of the observation interval \\
\hline
\end{tabular}

By combining (2) and (4)-(6), for wireless communication in the far-field region, the axial distance between the receiver and the sender should satisfy the following conditions:

$$
\begin{aligned}
& z \geq Z_{m n}^{V}=\frac{\operatorname{Cop}_{11}-\operatorname{Cop}_{m n}}{8.686\left(\alpha_{m n}^{V}-\alpha_{11}^{H}\right)}, \\
& z \geq Z_{m n}^{H}=\frac{\operatorname{Cop}_{11}-\operatorname{Cop}_{m n}}{8.686\left(\alpha_{m n}^{H}-\alpha_{11}^{H}\right)},
\end{aligned}
$$

where $Z_{m n}^{V}$ is the boundary of the zone where the attenuation of the vertically polarized $(m, n)$ mode is larger than that of the horizontally polarized $(1,1)$ mode; similarly, $Z_{m n}^{H}$ is the boundary for the horizontally polarized $(m, n)$ mode.

The optimal polarization estimation and zone division are as follows:

(1) If $\max \left(Z_{m n}^{H}\right)<\max \left(Z_{m n}^{V}\right)$, it can be inferred that higher-order modes for horizontal polarization attenuate more quickly than that for vertical polarization. Hence, before $\max \left(Z_{m n}^{V}\right)$, vertical polarization is 
optimal due to smaller path loss. There is a change in optimal polarization when the waves propagate along the tunnel axis.

In order to configure optimal polarization for the communication system, different propagation regions need to be distinguished. The location of the point dividing the regions is

$$
z_{\mathrm{DV}}=\max \left(Z_{m n}^{V}\right) \text {. }
$$

(2) If $\max \left(Z_{m n}^{H}\right) \geq \max \left(Z_{m n}^{V}\right)$, it means that higher-order modes for vertical polarization attenuate more quickly than that for horizontal polarization. Therefore, horizontally polarized field has a lower path loss in the zone close to the source. Then, there is no change in optimal polarization along the tunnel axis. It is unnecessary to divide the propagation regions and change the antenna polarization.

3.2.2. Statistical Methods. In order to verify the prediction, the following statistical method (SM) is used to identify the measured polarization difference and dividing point:

(1) Measure the distance-dependent signal power along the tunnel, and record the field power in decibels.

(2) Calculate the difference between the vertically polarized field power $P_{\mathrm{v}}$ and the horizontally polarized field power $P_{h}$. The power difference is represented as $\Delta P$, and $\Delta P=P_{\mathrm{v}}-P_{h}$.

(3) Calculate the mean value of $\Delta P$ per unit length. The mean value of $\Delta P$ per unit length is represented as $\overline{\Delta P}$.

The observation interval is the pseudoperiod of the field variation along the tunnel axis [23, 24]. The pseudoperiod of the field variation is expressed as $p$ and is deduced from the minima locations of $\Delta P$ [24]:

$$
p=\sqrt{\frac{1}{V} \sum_{v=2}^{V}\left|z_{v}-z_{v-1}\right|^{2}}
$$

where $z_{v}$ is the location of the $v$ th minimum of the power difference and $V$ is the total number of minima.

(4) Move the observation interval along the tunnel axis. Search the location of the observation interval, where $\overline{\Delta P}$ is equal to 0 . The location of the observation interval refers to the center of the interval, and its longitudinal coordinate is expressed as $z_{0.5}$.

(5) Search the furthest $z_{0.5}$, where the average $\Delta P$ is smaller than 0 before $z 0.5$ and greater than 0 after $z_{0.5}$. The furthest $z_{0.5}$ is the location of the dividing point between the near-field region and the far-field region. If there is no furthest $z_{0.5}$ that meets the aforementioned condition, it can be obtained that horizontal polarization is optimal in the both propagation zones, and there is no need to split the zones.

\section{Experimental Setup and Configuration}

For validation purposes, the distance-dependent field power is measured in two arched underground tunnels located at Xinglongzhuang Coal Mine, Shandong Province, China. One of the tunnels is wide. The tunnel has a cross-section radius of $2.69 \mathrm{~m}$, a flat bottom width of $5.12 \mathrm{~m}$, and a maximum height of $3.56 \mathrm{~m}$. The other tunnel is narrow. The tunnel has a cross-section radius of $1.54 \mathrm{~m}$, a flat bottom width of $2.82 \mathrm{~m}$, and a maximum height of $2.16 \mathrm{~m}$.

The grid-based system introduced in [13] is used to measure the electromagnetic field. The grid-based system can carry out multiple transceiver tests at the same time to improve the testing efficiency $[13,29]$. The diagram of the grid-based system is shown in Figure 2(b). Long-range measurements (up to $500 \mathrm{~m}$ in the wide tunnel) are needed in order to analyse the propagation characteristics in both near-field and far-field regions [20, 21]. High transmitting power and low receiving sensitivity are conducive to longrange measurements [30, 31]. $21 \mathrm{dBm}$ AS32-TTL and E22$900 \mathrm{~T}$ nodes are used in the grid-based system. Their receiving sensitivities are $-130 \mathrm{dBm}$ and $-148 \mathrm{dBm}$, respectively. AS32-TTL and E22-900T nodes operate at $433 \mathrm{MHz}$ and $900 \mathrm{MHz}$ frequencies, respectively. The antennas of the nodes are linearly polarized. The gain of the antennas is $4 \mathrm{dBi}$. Other antennas with different gains are also considered. Experimental results show that the antenna types and characteristics do not influence the effectiveness and feasibility of the proposed coverage optimization scheme. For the purpose of this paper, we do not describe the parameters of other antennas and the corresponding experimental results. Figure 2 and Tables 3-5 how the configuration of the measurements.

In the measurements, five fixed nodes simultaneously receive signals and provide the Received Signal Strength Indication (RSSI). The antenna nodes are, respectively, mounted at the tunnel center (C), ceiling center (CC), corner (CO), sidewall center (WC), and the widest part of the sidewall (WW). One node broadcasted signals at $\mathrm{C}$ point. The antenna position parameters are shown in Table 5. For each test, the average RSSI was recorded by calculation over 300 packets for 2 times. The average RSSI varied at most $\pm 1 \mathrm{dBm}$ from the mean value of the set of the test nodes. After each test, the transmitting node is moved backward along the tunnel by $1.40 \mathrm{~m}$ distance in the wide tunnel and $0.6 \mathrm{~m}$ distance in the narrow tunnel. The detailed description of the experimental system, node calibration, the signal transmitting and receiving, and the data recording can be found in [13].

\section{Results and Discussion}

Figure 3 shows $900 \mathrm{MHz}$ and $433 \mathrm{MHz}$ distance-dependent signal power measured in the wide tunnel and the narrow tunnel. The field is measured only by the horizontally polarized antennas or only by the vertically polarized antennas. 

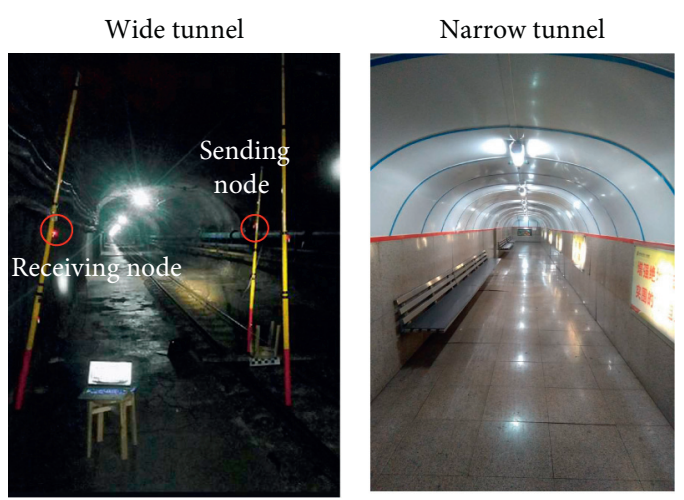

(a)

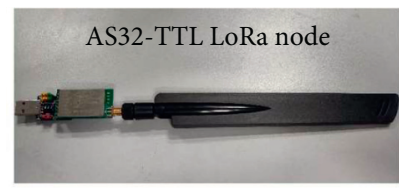

Position of receiving

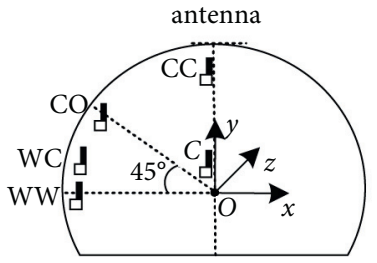

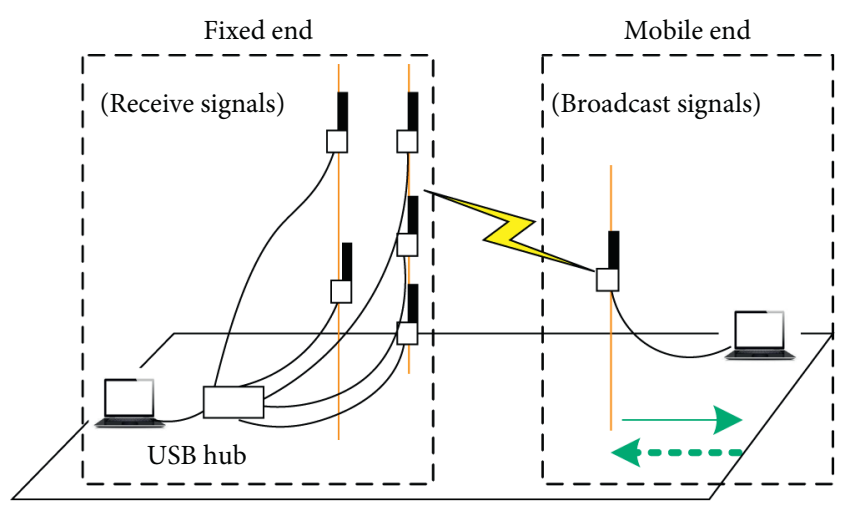

(b)

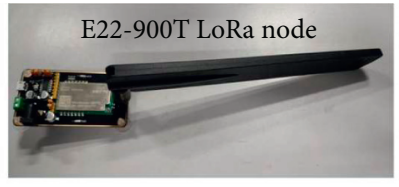

Position of sending

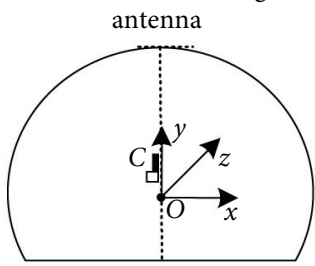

(c)

Figure 2: Measurement configuration. (a) Inside views of the tunnels. (b) Diagram of the measurement setup reported in [13]. (c) Details of LoRa nodes.

TABLE 3: Experimental settings: parameters of the measure tunnel.

\begin{tabular}{lcc}
\hline Parameters of cross-section & Wide tunnel & Narrow tunnel \\
\hline Shape & Arched & Arched \\
Radius & $2.69 \mathrm{~m}$ & $1.54 \mathrm{~m}$ \\
Floor width & $5.12 \mathrm{~m}$ & $2.82 \mathrm{~m}$ \\
Maximum height & $3.56 \mathrm{~m}$ & $2.16 \mathrm{~m}$ \\
\hline
\end{tabular}

TABLE 4: Experimental settings: details of LoRa nodes.

\begin{tabular}{lcc}
\hline Parameters & AS32-TTL node & E22-900T node \\
\hline Center frequency & $433 \mathrm{MHz}$ & $900 \mathrm{MHz}$ \\
Sending power & $21 \mathrm{dBm}$ & $21 \mathrm{dBm}$ \\
Receiving sensitivity & $-130 \mathrm{dBm}$ & $-148 \mathrm{dBm}$ \\
Antenna polarization & Linear & Linear \\
Antenna gain & $4 \mathrm{dBi}$ & $4 \mathrm{dBi}$ \\
\hline
\end{tabular}

TABLe 5: Experimental settings: locations of antennas.

\begin{tabular}{|c|c|c|c|c|c|}
\hline Antenna & Position of $\mathrm{C}$ & Position of CC & Position of $\mathrm{CO}$ & Position of WC & Position of WW \\
\hline \multicolumn{6}{|c|}{ Measurements in wide tunnel } \\
\hline Sending antenna & $\left(0,0.94, z_{1}\right)$ & - & - & - & - \\
\hline Receiving antenna & $(-0.28,0.89,0)$ & $(-0.04,2.40,0)$ & $(-1.62,1.90,0)$ & $(-2.30,0.90,0)$ & $(-2.45,0.02,0)$ \\
\hline \multicolumn{6}{|c|}{ Measurements in narrow tunnel } \\
\hline Sending antenna & $\left(0,0.46, z_{1}\right)$ & & & & \\
\hline Receiving antenna & $(0,0.46,0)$ & $(0,1.29,0)$ & $(0.89,1.06,0)$ & $(-1.20,0.46,0)$ & $(-1.20,0,0)$ \\
\hline
\end{tabular}



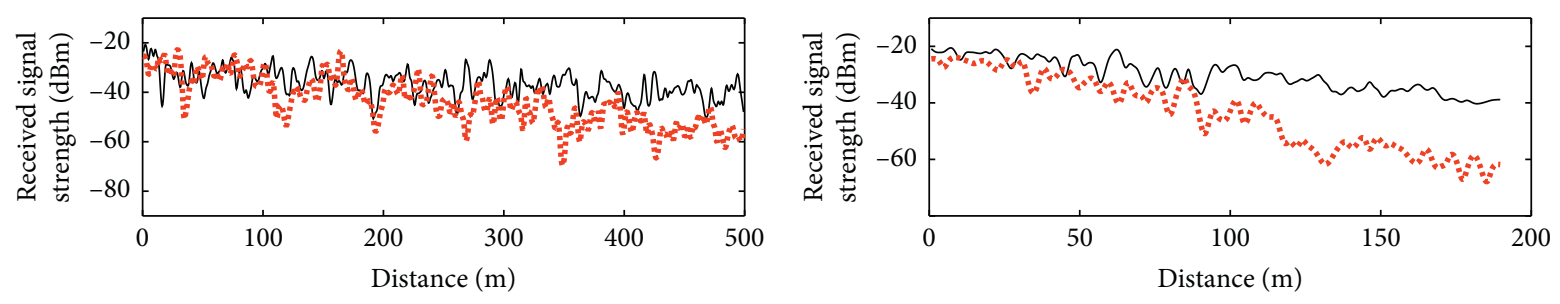

$-\mathrm{H}-\mathrm{C}$

- $\mathrm{H}-\mathrm{C}$

...... V-C

$\ldots . . . \quad \mathrm{V}-\mathrm{C}$
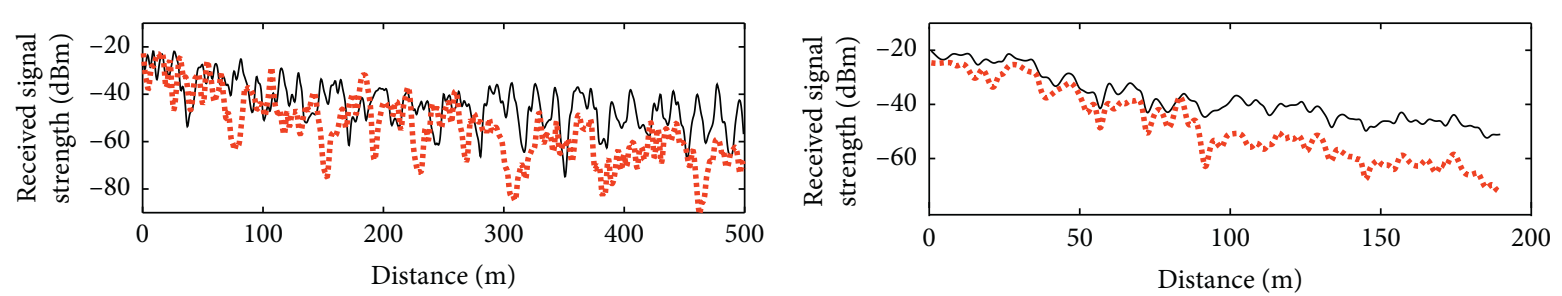

- $\mathrm{H}-\mathrm{CC}$

...... V-CC

- $\mathrm{H}-\mathrm{CC}$

...... V-CC
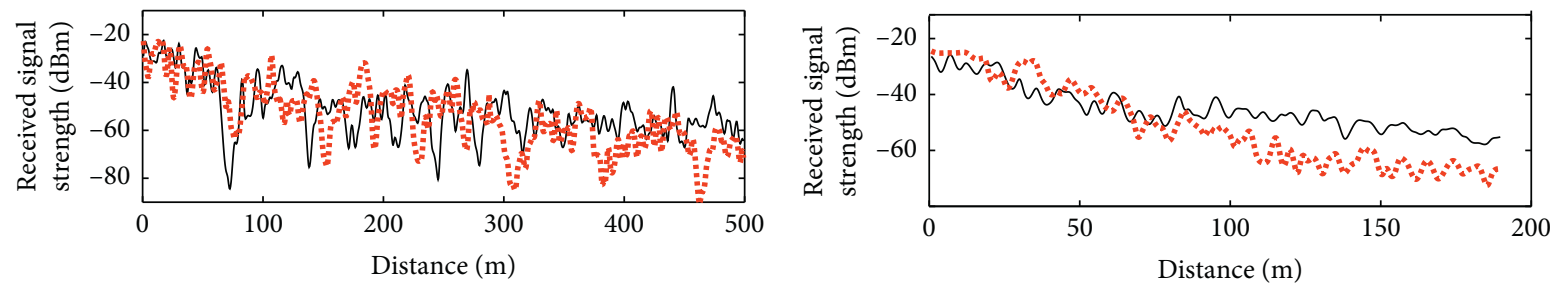

$-\mathrm{H}-\mathrm{CO}$

...... V-CO

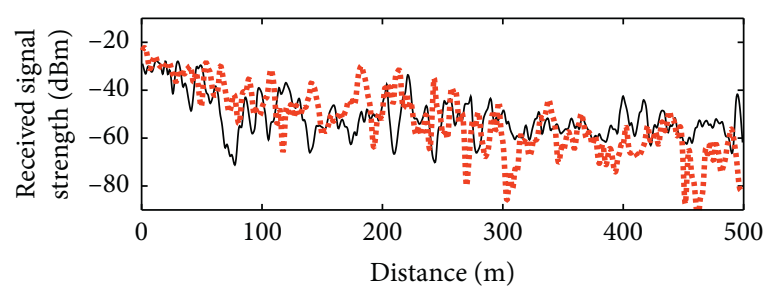

$-\mathrm{H}-\mathrm{CO}$

..... V-CO

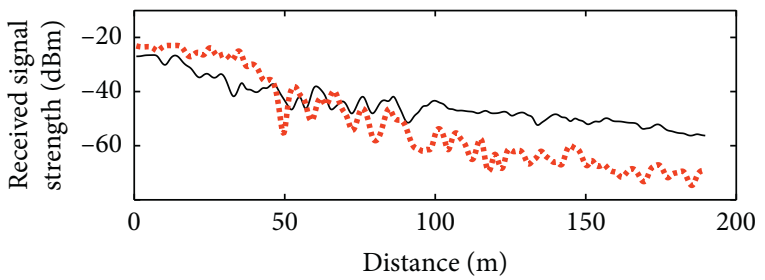

- $\mathrm{H}-\mathrm{WC}$

...... V-WC

- $\mathrm{H}-\mathrm{WC}$

...... V-WC
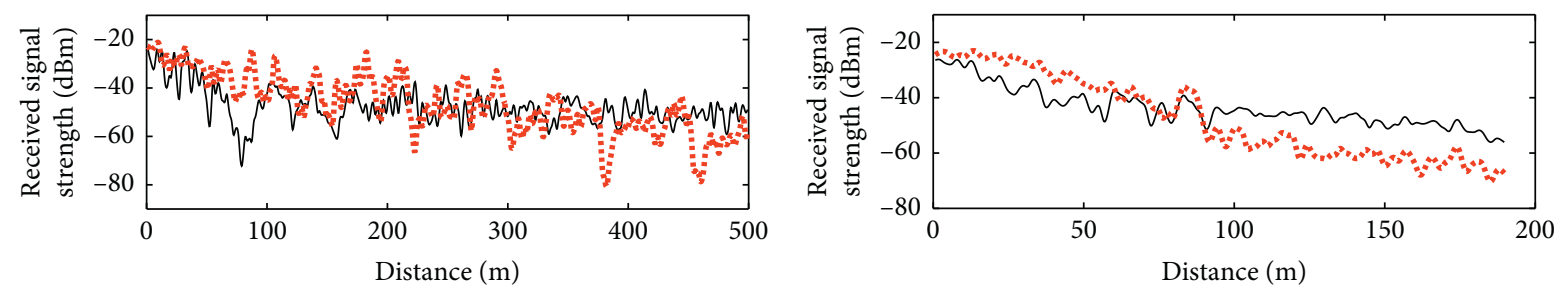

- H-WW

- $\mathrm{H}-\mathrm{WW}$

...... V-WW

...... V-WW

(a)

(b)

FIgURE 3: Continued. 

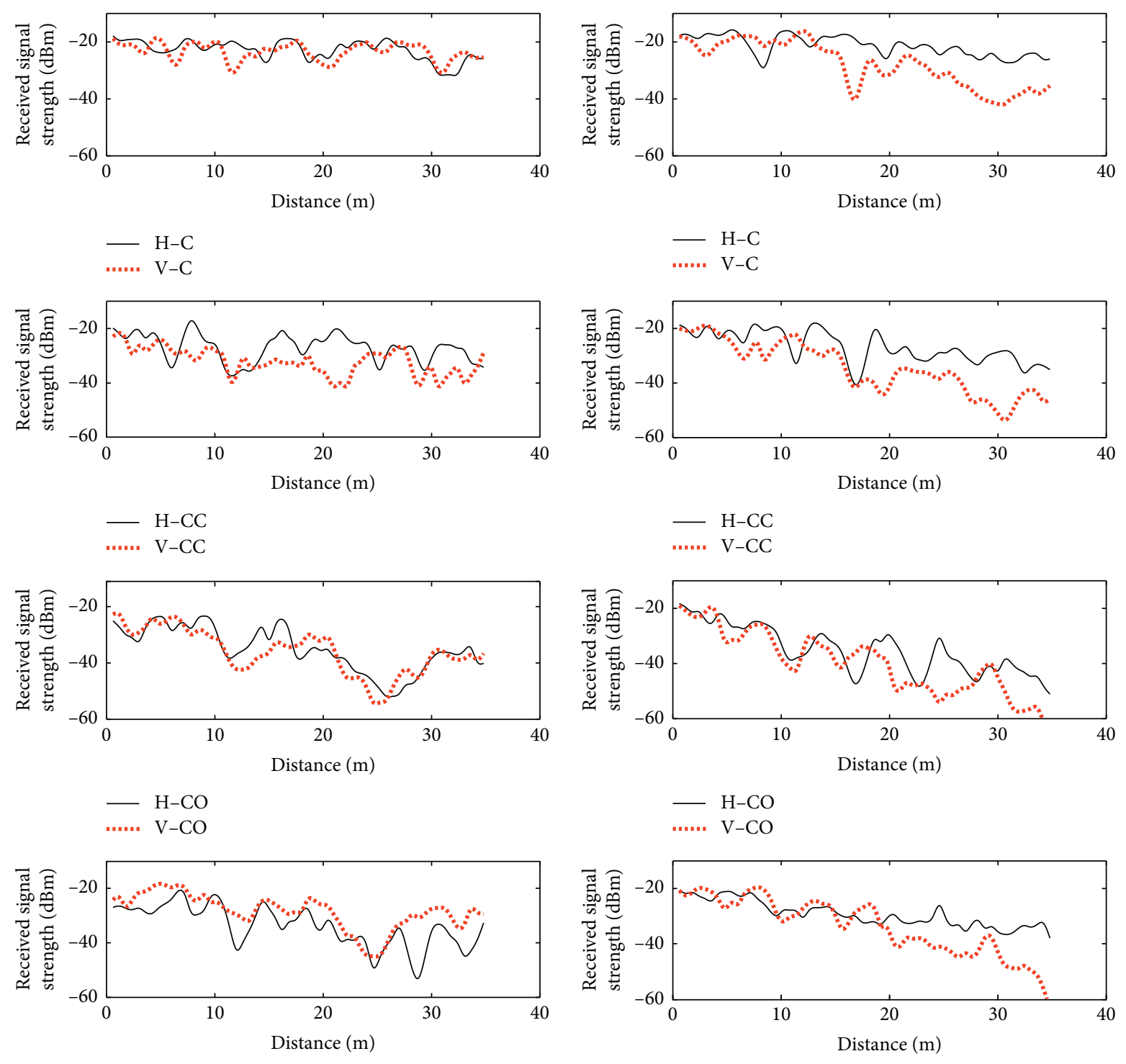

- H-WC

- H-WC

...... V-WC

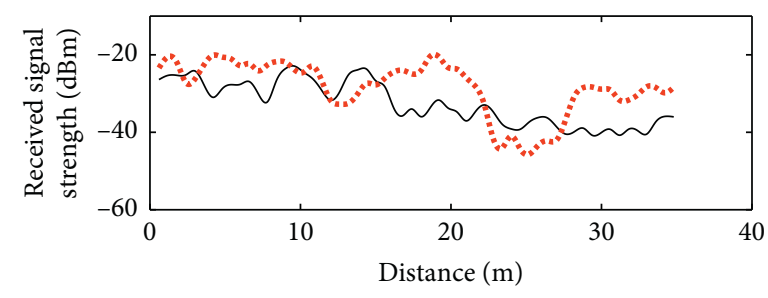

$\ldots . . . . \mathrm{V}-\mathrm{WC}$

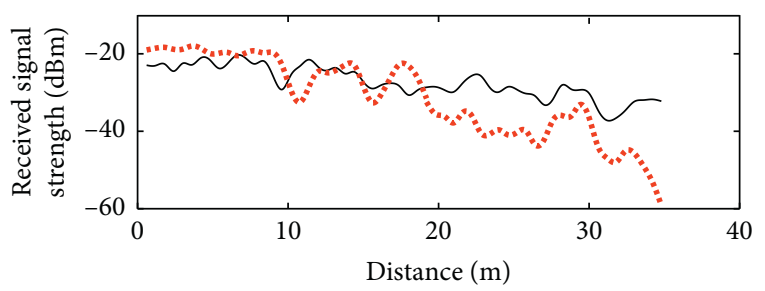

$\begin{array}{ll}- & \mathrm{H}-\mathrm{WW} \\ \cdots & \mathrm{V}-\mathrm{WW}\end{array}$

- H-WW

(..... V-WW

(c)

(d)

FIGURE 3: Distance-dependent signal power measured in the coal mine tunnel. $V$ indicates vertical polarization, and $H$ indicates horizontal polarization. (a) $900 \mathrm{MHz}$ signal in wide tunnel; (b) $433 \mathrm{MHz}$ signal in wide tunnel; (c) $900 \mathrm{MHz}$ signal in narrow tunnel; (d) $433 \mathrm{MHz}$ signal in narrow tunnel. 


\begin{tabular}{|c|c|c|c|c|c|}
\hline & \multicolumn{3}{|l|}{ Parameter } & Wide tunnel & Narrow tunnel \\
\hline & \multicolumn{3}{|l|}{ Tunnel size } & $\begin{array}{l}w=5.10 \mathrm{~m} \\
h=3.43 \mathrm{~m}\end{array}$ & $\begin{array}{l}w=2.92 \mathrm{~m} \\
h=2.06 \mathrm{~m}\end{array}$ \\
\hline CO $\because \because$ CC & \multicolumn{3}{|l|}{ Frequency } & $\begin{array}{l}900 \mathrm{MHz} / \\
433 \mathrm{MHz}\end{array}$ & $\begin{array}{l}900 \mathrm{MHz} / \\
433 \mathrm{MHz}\end{array}$ \\
\hline WWD & \multicolumn{3}{|c|}{$\begin{array}{l}\text { Electrical parameters } \\
\text { of ceiling [31] }\end{array}$} & 10 & 10 \\
\hline$\longleftarrow \begin{array}{l} \\
\longleftarrow\end{array}$ & \multicolumn{3}{|c|}{$\begin{array}{l}\text { Electrical parameters } \\
\text { of side walls [31] }\end{array}$} & 15 & 15 \\
\hline & \multirow{6}{*}{$\begin{array}{l}\text { Coordinates } \\
\text { of antennas }\end{array}$} & \multirow{5}{*}{$\begin{array}{l}\text { Fixed } \\
\text { end }\end{array}$} & $\mathrm{C}$ & $(-0.28,0,0)$ & $(0,0,0)$ \\
\hline & & & $\mathrm{CC}$ & $(-0.08,1.43,0)$ & $(0,0.79,0)$ \\
\hline & & & $\mathrm{CO}$ & $(-2.15,1.42,0)$ & $(-1.16,0.81,0)$ \\
\hline & & & WC & $(-2.30,0.95,0)$ & $(-1.20,0.37,0)$ \\
\hline & & & WW & $(-2.31,0.14,0)$ & $(-1.14,0.22,0)$ \\
\hline & & $\begin{array}{l}\text { Mobile } \\
\text { end }\end{array}$ & $\mathrm{C}$ & $(0,0.06, z)$ & $(0,0, z)$ \\
\hline
\end{tabular}

FIGURE 4: Simulation parameters of the equivalently surrogated tunnel.

TABLE 6: Maximum boundary for horizontal polarization modes and vertical polarization modes at $900 \mathrm{MHz}$ frequency in the wide tunnel (in $\mathrm{m}$ ).

\begin{tabular}{lccccc}
\hline Polarization & Position of C & Position of CC & Position of CO & Position of WC & Position of WW \\
\hline Horizontal & 0 & 269.94 & 268.08 & 79.09 & 79.28 \\
\hline Vertical & 0 & 25.03 & 293.29 & 307.97 & 308.70 \\
\hline
\end{tabular}

Figure 3(b) has been reported in [13], and other data is expanded in this paper.

\subsection{Optimal Polarization Estimation and Zone Division.} To simplify the solution of the proposed method, the measured tunnels are equivalently surrogated by rectangular tunnels by using the method reported in [23]. The simulation parameters are presented in Figure 4.

Firstly, we show an example of the optimal polarization estimation and zone division by using the proposed method for $900 \mathrm{MHz}$ field coverage in the wide tunnel.

5.1.1. MM. The boundary of the zones where the power attenuation of the higher-order mode is larger than the fundamental mode is calculated by using (7). The maximum boundaries for horizontal polarization and vertical polarization are shown in Table 6.

Compare the results in Table 6. It can be observed that the maximum boundary for horizontal polarization is smaller than that for vertical polarization, when the signal is received at the position of $\mathrm{CO}, \mathrm{WC}$, and $\mathrm{WW}$. The opposite results appear when the signal is received at the position of $\mathrm{C}$ and CC.

As illustrated in Section 3.2.1, when the signal is received at the position of $\mathrm{CO}, \mathrm{WC}$, and $\mathrm{WW}$, vertical polarization is optimal in the near-field region. There is a change in optimal polarization when the signal travels along the tunnel axis. When the receiver is fixed at the position of $\mathrm{C}$ and $\mathrm{CC}$, horizontal polarization is optimal, and there is no change in optimal polarization when the signal travels along the tunnel axis.

For the receiver mounted at the position of $\mathrm{CO}, \mathrm{WC}$, and WW, the propagation regions are divided into a near-field region and a far-field region by a dividing point at $293.29 \mathrm{~m}$, $307.97 \mathrm{~m}$, and $308.70 \mathrm{~m}$, respectively. The corresponding range of the near-field region is from $0 \mathrm{~m}-293.29 \mathrm{~m}$, $0 \mathrm{~m}-307.97 \mathrm{~m}$, and $0 \mathrm{~m}-308.70 \mathrm{~m}$, respectively. For the receiver mounted at $\mathrm{C}$ and $\mathrm{CC}$ positions, zone division is unnecessary.

5.1.2. SM. $900 \mathrm{MHz}$ measured field distribution in the wide tunnel is shown in Figure 3(a).

The difference between the vertically and the horizontally polarized field power $\Delta P$ is plotted in Figure 5 . The smoothing spline filter is used to reduce the influence of the noise on the data and to facilitate the analysis of the field variation. The pseudoperiod of the field variation measured at the positions of $\mathrm{C}, \mathrm{CC}, \mathrm{CO}, \mathrm{WC}$, and $\mathrm{WW}$ are $103.88 \mathrm{~m}$, $81.19 \mathrm{~m}, 62.68 \mathrm{~m}, 71.64 \mathrm{~m}$, and $63.50 \mathrm{~m}$, respectively.

Take the pseudoperiod of the field variation as the observation unit, and then calculate the mean value of $\Delta P$ per unit length. The results are shown in Figure 6.

It can be noted that when the receiver is located at the position of $\mathrm{CO}, \mathrm{WC}$, and $\mathrm{WW}$, vertical polarization results in less average path loss in the near-field region, while horizontal polarization results in less average path loss in the far-field region. The corresponding measured dividing points of the regions are located at $274.20 \mathrm{~m}, 248.60 \mathrm{~m}$, and 

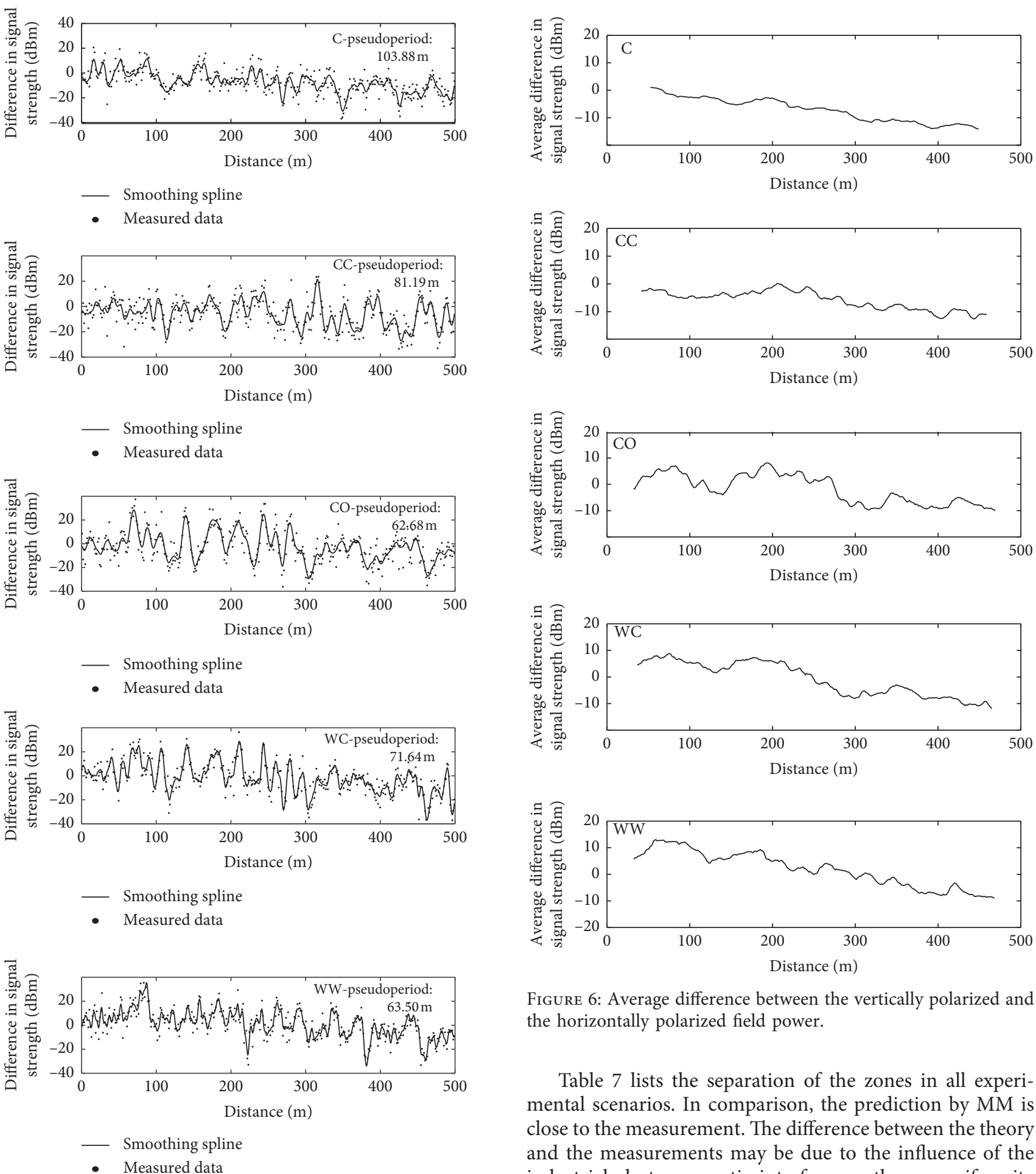

Figure 5: Difference between the vertically polarized and the horizontally polarized field power.

$317.30 \mathrm{~m}$, respectively. The corresponding range of the nearfield region is from $0 \mathrm{~m}-274.20 \mathrm{~m}, 0 \mathrm{~m}-248.60 \mathrm{~m}$, and $0 \mathrm{~m}-317.30 \mathrm{~m}$, respectively. When the receiver is located at the point of $\mathrm{C}$ and $\mathrm{CC}$, there is no change in optimal polarization along the tunnel axis, and it is unnecessary to divide the propagation regions.

Figure 6: Average difference between the vertically polarized and the horizontally polarized field power.

Table 7 lists the separation of the zones in all experimental scenarios. In comparison, the prediction by $\mathrm{MM}$ is close to the measurement. The difference between the theory and the measurements may be due to the influence of the industrial electromagnetic interference, the nonuniformity of scatters, materials, and shapes present in coal mine tunnels.

The dividing points estimated by the proposed method are also compared with the existing methods based on FBP [16-20] and SI [21, 22]. There are two dividing points determined by SI for each experimental scenario. One is deduced from the horizontally polarized field, and the other is deduced from the vertically polarized field. As listed in Table 7, the dividing points determined by FBP and SI are usually different from the measured dividing points. The 
TABLe 7: Location of dividing point (in $\mathrm{m}$ ).

\begin{tabular}{|c|c|c|c|c|c|}
\hline \multirow{2}{*}{ Method } & \multicolumn{5}{|c|}{ Receiver Position } \\
\hline & $\mathrm{C}$ & $\mathrm{CC}$ & $\mathrm{CO}$ & WC & WW \\
\hline \multicolumn{6}{|c|}{$900 \mathrm{MHz}$-wide tunnel } \\
\hline MM & - & - & 293.28 & 307.97 & 308.70 \\
\hline SM & - & - & 274.20 & 248.60 & 317.30 \\
\hline FBP & 77.98 & 77.98 & 77.98 & 77.98 & 77.98 \\
\hline SI-H & 143.50 & 200.90 & 350.70 & 454.30 & 469.70 \\
\hline SI-V & 46.90 & 91.70 & 101.50 & 95.90 & 76.30 \\
\hline \multicolumn{6}{|c|}{$433 \mathrm{MHz}$-wide tunnel } \\
\hline MM & - & - & 67.53 & 70.92 & 71.09 \\
\hline SM & - & - & 62.18 & 57.21 & 83.76 \\
\hline FBP & 37.51 & 37.51 & 37.51 & 37.51 & 37.51 \\
\hline SI-H & 13.30 & 51.10 & 67.90 & 62.30 & 69.30 \\
\hline SI-V & 120.30 & 38.50 & 118.30 & 94.50 & 94.50 \\
\hline \multicolumn{6}{|c|}{$900 \mathrm{MHz}$-narrow tunnel } \\
\hline $\mathrm{MM}$ & - & - & 61.30 & 63.22 & 59.76 \\
\hline SM & - & - & - & $>34.80$ & $>34.80$ \\
\hline FBP & 25.66 & 25.66 & 25.66 & 25.66 & 25.66 \\
\hline SI-H & - & - & - & - & - \\
\hline SI-V & - & - & - & - & - \\
\hline \multicolumn{6}{|c|}{$433 \mathrm{MHz}$-narrow tunnel } \\
\hline MM & - & - & 13.75 & 14.50 & 13.64 \\
\hline SM & - & - & - & 17.19 & 14.34 \\
\hline FBP & 12.34 & 12.34 & 12.34 & 12.34 & 12.34 \\
\hline SI-H & 5.40 & 7.20 & 13.20 & 13.80 & - \\
\hline SI-V & - & 7.20 & 3.60 & - & - \\
\hline
\end{tabular}

TABLE 8: List of coverage schemes for comparison.

\begin{tabular}{lc}
\hline Coverage scheme & Description \\
\hline $\begin{array}{l}\text { Strategy-H }[11,13] \\
\text { Strategy-V [12] }\end{array}$ & Coverage without zone division; use the horizontally polarized antennas \\
Strategy-MM & Coverage without zone division; use the vertically polarized antennas \\
Strategy-SM & Coverage with zone division by using MM \\
$\begin{array}{l}\text { Strategy-FBP } \\
\text { Strategy-SI-H }\end{array}$ & Coverage with zone division by using SM \\
Strategy-SI-V & Coverage with zone division by using FBP [16-20] \\
\hline
\end{tabular}

reason is that FBP and SI do not capture the polarization difference in the path loss.

From Table 7, the dividing point is farther from the transmitter for larger tunnel or higher frequency. This result is consistent with the previous study in [18-21]. The reason is that larger tunnel size and higher frequencies can excite more modes with lower path loss [18-21]. The nearfield region where the field consists of many modes is expanded.

5.2. Coverage Optimization. According to the aforementioned results obtained from MM and SM, zone division is unnecessary for nodes installed at $\mathrm{C}$ and $\mathrm{CC}$ points, but necessary for nodes installed at $\mathrm{CO}, \mathrm{WC}$, and $\mathrm{WW}$ points. By using coverage optimization introduced in Section 3.1, we adopt horizontal polarization to communicate with the nodes fixed at $\mathrm{C}$ and $\mathrm{CC}$ points. We optimize the field coverage of the nodes fixed at $\mathrm{CO}, \mathrm{WC}$, and $\mathrm{WW}$ through polarization switching. The proposed coverage scheme and other coverage schemes [11-13] are also compared in this section. Table 8 lists the coverage schemes for comparison.

Figure 7 shows an example of $900 \mathrm{MHz}$ field distribution covered by a node fixed at the WW point in the wide tunnel. In Figure 7, DP-MM/SM/FBP/SI represents the dividing point determined by MM/SM/FBP/SI. SI-H/V represents SI based on the horizontally/vertically polarized field. Figure 7 (a) provides the cumulative probability of RSSI. It can be seen that the signal power covered by the proposed strategy (Strategy-MM/SM) is much larger than that covered by other strategies. Figure 7(b) shows the distance-dependent signal power. It can be seen that Strategy-FBP and Strategy-SI-H/V lead to unreasonable zone division and polarization switching and obtain higher path loss in some propagation regions. To further analyse the significant impact of zone division on the optimized performance of the wireless coverage, Tables 9 and 10 list the average path loss covered by different strategies in different propagation regions. In all experimental scenarios, the results by StrategyMM are consistent with Strategy-SM. For Strategy-FBP, the average path loss from DP-MM to DP-FBP tends to be larger 


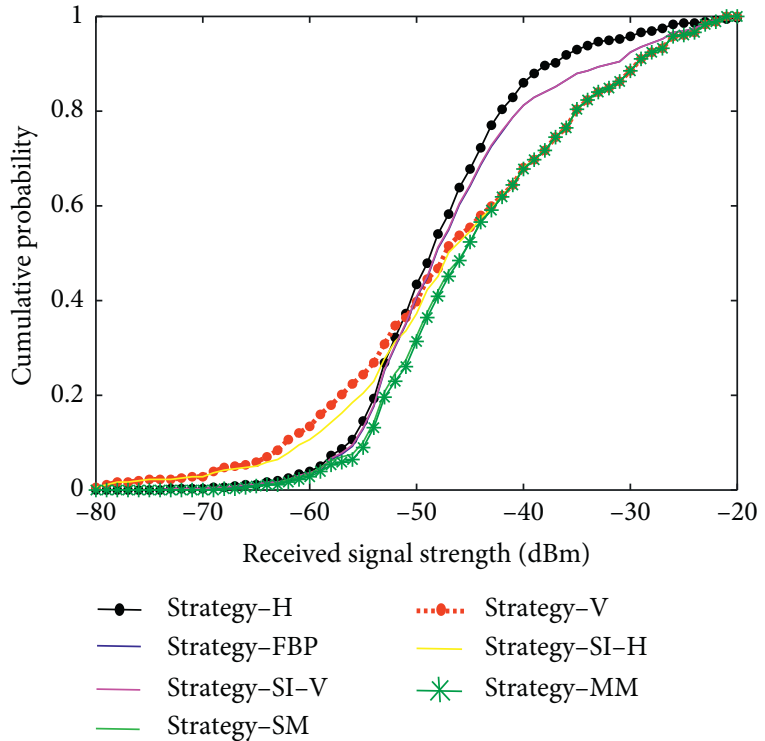

(a)

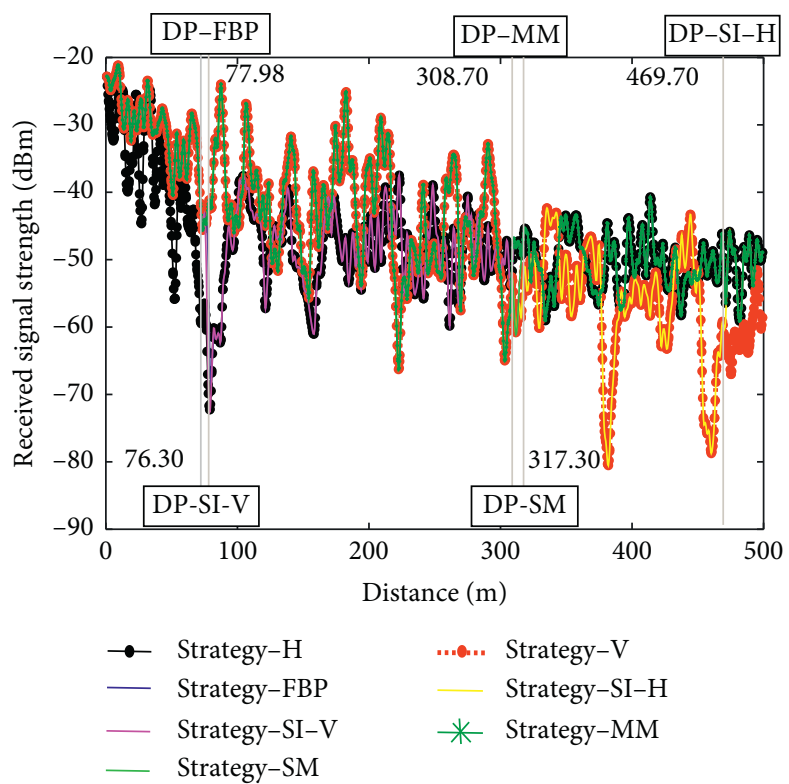

(b)

FIGURE 7: $900 \mathrm{MHz}$ coverage with and without coverage optimization. (a) Cumulative probability of RSSI. (b) Distance-dependent signal power.

TABLE 9: Average field power in different propagation regions (in $\mathrm{dBm}$ ): coverage in the wide tunnel.

\begin{tabular}{|c|c|c|c|c|c|c|c|c|c|}
\hline \multirow{3}{*}{$\begin{array}{l}\text { Coverage } \\
\text { strategy }\end{array}$} & \multirow{2}{*}{\multicolumn{3}{|c|}{ Position of $\mathrm{CO}$}} & \multirow{2}{*}{\multicolumn{3}{|c|}{$\begin{array}{c}\text { Position of WC } \\
\text { Propagation region }\end{array}$}} & \multicolumn{3}{|c|}{ Position of WW } \\
\hline & & & & & & & & & \\
\hline & $\begin{array}{l}\text { DP-MM to } \\
\text { DP-FBP }\end{array}$ & $\begin{array}{l}\text { DP-MM to } \\
\text { DP-SI-H }\end{array}$ & $\begin{array}{l}\text { DP-MM to } \\
\text { DP-SI-V }\end{array}$ & $\begin{array}{l}\text { DP-MM to } \\
\text { DP-FBP }\end{array}$ & $\begin{array}{l}\text { DP-MM to } \\
\text { DP-SI-H }\end{array}$ & $\begin{array}{l}\text { DP-MM to } \\
\text { DP-SI-V }\end{array}$ & $\begin{array}{l}\text { DP-MM to } \\
\text { DP-FBP }\end{array}$ & $\begin{array}{l}\text { DP-MM to } \\
\text { DP-SI-H }\end{array}$ & $\begin{array}{l}\text { DP-MM to } \\
\text { DP-SI-V }\end{array}$ \\
\hline \multicolumn{10}{|c|}{$900 \mathrm{MHz}$-wide tunnel } \\
\hline $\begin{array}{l}\text { Strategy- } \\
\text { MM }\end{array}$ & -49.85 & -55.26 & -50.41 & -49.83 & -55.37 & -50.26 & -43.14 & -50.35 & -43.09 \\
\hline Strategy-SM & -50.36 & -55.26 & -50.99 & -47.94 & -55.37 & -48.22 & -43.21 & -50.88 & -43.09 \\
\hline Strategy-FBP & -51.88 & -55.26 & -52.33 & -51.42 & -55.37 & -51.32 & -48.41 & -50.35 & -48.53 \\
\hline $\begin{array}{l}\text { Strategy-SI- } \\
\mathrm{H}\end{array}$ & -49.85 & -64.65 & -50.41 & -49.83 & -61.27 & -50.26 & -43.21 & -56.16 & -43.09 \\
\hline $\begin{array}{l}\text { Strategy-SI- } \\
\text { V }\end{array}$ & -51.55 & -55.26 & -52.33 & -50.80 & -55.37 & -51.32 & -48.41 & -50.35 & -48.71 \\
\hline Strategy-H & -51.88 & -55.26 & -52.33 & -51.42 & -55.37 & -51.32 & -48.41 & -50.35 & -48.71 \\
\hline Strategy-V & -49.85 & -64.65 & -50.41 & -49.83 & -61.27 & -50.26 & -43.21 & -56.16 & -43.09 \\
\hline \multicolumn{10}{|c|}{$433 \mathrm{MHz}$-wide tunnel } \\
\hline $\begin{array}{l}\text { Strategy- } \\
\text { MM }\end{array}$ & -37.11 & -43.95 & -44.41 & -38.44 & -40.51 & -42.97 & -32.68 & -35.78 & -41.60 \\
\hline Strategy-SM & -37.40 & -43.95 & -44.41 & -37.37 & -42.02 & -42.97 & -32.68 & -35.78 & -41.35 \\
\hline Strategy-FBP & -39.68 & -43.95 & -44.41 & -38.73 & -42.02 & -42.97 & -38.34 & -37.34 & -41.60 \\
\hline $\begin{array}{l}\text { Strategy-SI- } \\
\mathrm{H}\end{array}$ & -37.11 & -42.62 & -44.40 & -38.45 & -42.02 & -42.97 & -32.74 & -37.34 & -41.60 \\
\hline $\begin{array}{l}\text { Strategy-SI- } \\
\text { V }\end{array}$ & -37.11 & -49.54 & -51.40 & -38.44 & -40.51 & -49.83 & -32.68 & -35.78 & -41.86 \\
\hline Strategy-H & -39.68 & -43.95 & -44.41 & -38.73 & -42.02 & -42.97 & -38.34 & -37.34 & -41.60 \\
\hline Strategy-V & -37.11 & -49.54 & -51.40 & -38.44 & -40.51 & -49.83 & -32.68 & -35.78 & -41.86 \\
\hline
\end{tabular}

because the estimated near-field region is usually smaller (Table 7), and the antenna polarization is changed earlier. From DP-MM to DP-FBP, the average path loss of StrategyFBP can exceed that of Strategy-MM 8.99 dBm. For Strategy-
SI, the average path loss from DP-MM to DP-SI is usually larger because the estimated near-field region is either smaller or larger (Table 7), and the antenna polarization is switched either earlier or later. From DP-MM to DP-SI, the 
TABLE 10: Average field power in different propagation regions (in $\mathrm{dBm}$ ): coverage in the narrow tunnel.

\begin{tabular}{|c|c|c|c|c|c|c|c|c|c|}
\hline \multirow{3}{*}{$\begin{array}{l}\text { Coverage } \\
\text { strategy }\end{array}$} & \multirow{2}{*}{\multicolumn{3}{|c|}{ Position of $\mathrm{CO}$}} & \multirow{2}{*}{\multicolumn{3}{|c|}{$\begin{array}{c}\text { Position of WC } \\
\text { Propagation region }\end{array}$}} & \multirow{2}{*}{\multicolumn{3}{|c|}{ Position of WW }} \\
\hline & & & & & & & & & \\
\hline & $\begin{array}{l}\text { DP-MM to } \\
\text { DP-FBP }\end{array}$ & $\begin{array}{l}\text { DP-MM to } \\
\text { DP-SI-H }\end{array}$ & $\begin{array}{l}\text { DP-MM to } \\
\text { DP-SI-V }\end{array}$ & $\begin{array}{l}\text { DP-MM } \\
\text { to D }\end{array}$ & $\begin{array}{l}\text { DP-MM to } \\
\text { DP-SI-H }\end{array}$ & $\begin{array}{l}\text { DP-MM to } \\
\text { DP-SI-V }\end{array}$ & $\begin{array}{l}\text { DP-MM to } \\
\text { DP-FBP }\end{array}$ & $\begin{array}{l}\text { DP-MM to } \\
\text { DP-SI-H }\end{array}$ & $\begin{array}{l}\text { DP-MM to } \\
\text { DP-SI-V }\end{array}$ \\
\hline \multicolumn{10}{|c|}{$900 \mathrm{MHz}$-narrow tunnel } \\
\hline Strategy-MM & -41.13 & - & - & -31.15 & - & - & -32.37 & - & - \\
\hline Strategy-SM & -41.93 & - & - & -31.15 & - & - & -32.37 & - & - \\
\hline Strategy-FBP & -41.93 & - & - & -40.14 & - & - & -38.74 & - & - \\
\hline $\begin{array}{l}\text { Strategy-SI- } \\
\mathrm{H}\end{array}$ & -41.93 & - & - & -40.14 & - & - & -38.74 & - & - \\
\hline $\begin{array}{l}\text { Strategy-SI- } \\
\text { V }\end{array}$ & -41.93 & - & - & -40.14 & - & - & -38.74 & - & - \\
\hline Strategy-H & -41.93 & - & - & -40.14 & - & - & -38.74 & - & - \\
\hline Strategy- V & -41.13 & - & - & -31.15 & - & - & -32.37 & - & - \\
\hline \multicolumn{10}{|c|}{$433 \mathrm{MHz}$-narrow tunnel } \\
\hline Strategy-MM & -30.53 & -32.99 & -32.01 & -25.27 & -25.14 & - & -24.65 & - & - \\
\hline Strategy-SM & -33.04 & -30.25 & -29.40 & -25.27 & -25.14 & - & -24.65 & - & - \\
\hline Strategy-FBP & -33.04 & -30.25 & -32.32 & -26.55 & -25.76 & - & -24.85 & - & - \\
\hline $\begin{array}{l}\text { Strategy-SI- } \\
\mathrm{H}\end{array}$ & -30.53 & -32.99 & -32.01 & -25.42 & -25.76 & - & -24.85 & - & - \\
\hline $\begin{array}{l}\text { Strategy-SI- } \\
\text { V }\end{array}$ & -33.04 & -30.25 & -29.40 & -26.55 & -25.76 & - & -24.85 & - & - \\
\hline Strategy-H & -33.04 & -30.25 & -29.40 & -26.55 & -25.76 & - & -24.85 & - & - \\
\hline Strategy-V & -30.53 & -32.99 & -32.01 & -25.27 & -25.14 & - & -24.65 & - & - \\
\hline
\end{tabular}

average path loss of Strategy-SI can exceed that of StrategyMM $9.39 \mathrm{dBm}$.

\section{Conclusions}

This paper applies zone division and polarization switching to coverage optimization of the wireless system in underground tunnels. A multimodal approach is proposed to estimate the axial variation of the optimal antenna polarization along the tunnel for zone division. Extensive measurements are conducted to validate the effectiveness and feasibility of the coverage optimization. Compared with coverage that only uses a single polarization in the entire propagation region, polarization switching based on reasonable zone division can reduce the power attenuation of the signal. Meanwhile, we compare the performance of our proposed method with that of the existing zone-division methods based on the Fresnel breakpoint and system identification. Results show that zone division has an important influence on the optimized performance of the wireless coverage. The zones divided by the existing methods are too small or too large, which results in incorrect polarization switching and higher average path loss. It is more reasonable to switch polarization based on the proposed zone-division method.

The proposed coverage scheme requires repeated user positioning, zone division, and polarization configuration. However, there is no need to repeatedly call the coverage optimization procedure, when the user is relatively static or is always in one of the propagation zones during communication. The efficiency of the coverage optimization program can be further improved by optimizing the repetition cycle of the program with the information of the user's movement direction and speed.

The proposed coverage optimization and zone division can also provide solutions for other wireless energy efficiency related problems in underground tunnels such as wireless charging and network connectivity.

\section{Data Availability}

The data used to support the findings of this study are included within the article and also are available from the corresponding author upon request.

\section{Conflicts of Interest}

The authors declare that there are no conflicts of interest regarding the publication of this paper.

\section{Acknowledgments}

The authors express their thanks to the supports from the National Natural Science Foundation of China under Grants 61901475, 61841114, 51874299, and 62071472 and National Key Research and Development Project under Grant 2017 YFC0804404.

\section{References}

[1] A. E. Forooshani, S. Bashir, D. G. Michelson, and S. Noghanian, "A survey of wireless communications and propagation modeling in underground mines," IEEE Communications Surveys \& Tutorials, vol. 15, no. 4, pp. 1524-1545, 2013. 
[2] A. Hrovat, G. Kandus, and T. Javornik, "A survey of radio propagation modeling for tunnels," IEEE Communications Surveys \& Tutorials, vol. 16, no. 2, pp. 658-669, 2013.

[3] S. Yarkan, S. Guzelgoz, H. Arslan, and R. Murphy, "Underground mine communications: a survey," IEEE Communications Surveys \& Tutorials, vol. 11, no. 3, pp. 125-142, 2009.

[4] A. Ranjan, Y. Zhao, H. B. Sahu, and P. Misra, "Opportunities and challenges in health sensing for extreme industrial environment: perspectives from underground mines," IEEE Access, vol. 7, pp. 139181-139195, 2019.

[5] A. Ranjan, H. B. Sahu, and P. Misra, "Wireless sensor networks," International Journal of Applied Evolutionary Computation, vol. 7, no. 4, pp. 1-27, 2016.

[6] S.-D. Li, Y.-J. Liu, L.-K. Lin et al., "Channel measurements and modeling at $6 \mathrm{GHz}$ in the tunnel environments for $5 \mathrm{G}$ wireless systems," International Journal of Antennas and Propagation, vol. 2017, Article ID 1513038, 15 pages, 2017.

[7] Z. Ren, F. Zhang, G. Zheng, A. Saleem, and K. Guan, “A 3D non-stationary channel model with moving mobile station in rectangular tunnel," International Journal of Antennas and Propagation, vol. 2019, Article ID 6750153, 12 pages, 2019.

[8] Q. Hu, J. Yang, R. Zhang, W. Chen, and B. Li, "Distributed cooperative wireless charging for the mine internet of things," IEEE Access, vol. 7, pp. 81000-81009, 2019.

[9] D. Li and J. Wang, "Effect of antenna parameters on the field coverage in tunnel environments," International Journal of Antennas and Propagation, vol. 2016, Article ID 8180124, 10 pages, 2016.

[10] Z. Zhao, J. Wang, W. Hou, Y. Li, and B. Ai, "Optimized scheme of antenna diversity for radio wave coverage in tunnel environment," IEEE Access, vol. 8, pp. 127226-127233, 2020.

[11] C. Zhou, T. Plass, R. Jacksha, and J. A. Waynert, "RF Propagation in mines and tunnels: extensive measurements for vertically, horizontally, and cross-polarized signals in mines and tunnels," IEEE Antennas and Propagation Magazine, vol. 57, no. 4, pp. 88-102, 2015.

[12] S. Bashir, "Effect of antenna position and polarization on UWB propagation channel in underground mines and tunnels," IEEE Transactions on Antennas and Propagation, vol. 62, no. 9, pp. 4711-4779, 2014.

[13] Y. Huo, L. Zhao, Q. S. Hu, E. J. Ding, X. H. Zhao, and Z. Sun, "Optimal deployment of antenna for field coverage in coal mine tunnels," IEEE Access, vol. 8, no. 1, pp. 2169-3536, 2020.

[14] A. Emslie, R. Lagace, and P. Strong, "Theory of the propagation of UHF radio waves in coal mine tunnels," IEEE Transactions on Antennas and Propagation, vol. 23, no. 2, pp. 192-205, 1975.

[15] Y. P. Zhang, G. X. Zheng, and J. H. Sheng, "Excitation of UHF radio waves in tunnels," Microwave and Optical Technology Letters, vol. 22, no. 6, pp. 408-410, 1999.

[16] K. Guan, Z. Zhong, B. Ai, R. He, Y. Li, and C. Briso, "Propagation mechanism modeling in the near-region of arbitrary cross-sectional tunnels," International Journal of Antennas and Propagation, vol. 2012, Article ID 183145, 11 pages, 2012.

[17] K. Guan, Z. Zhong, B. Ai, and C. Briso, "Research of propagation characteristics of break point: near zone and far zone under operational subway condition," in Proceedings of the 6th International Wireless Communications and Mobile Computing Conference, pp. 114-118, Caen, France, June 2010.

[18] C. Briso, J. M. Cruz, and J. I. Alonso, "Measurements and modeling of distributed antenna systems in railway tunnels," IEEE Transactions on Vehicular Technology, vol. 56, no. 5, pp. 2870-2879, Sep. 2007.
[19] Y. P. Zhang, "Novel model for propagation loss prediction in tunnels," IEEE Transactions on Vehicular Technology, vol. 52, no. 5, pp. 1308-1314, 2003.

[20] Y. P. Zhang, "Enhancement of waveguide model for propagation-loss prediction in tunnels," Microwave and Optical Technology Letters, vol. 30, pp. 10-12, 2001.

[21] D. G. Dudley, H.-Y Pao, and H.-Y Pao, "System identification for wireless propagation channels in tunnels," IEEE Transactions on Antennas and Propagation, vol. 53, no. 8, pp. 2400-2405, 2005.

[22] D. Dudley, M. Lienard, S. Mahmoud, and P. Degauque, "Wireless propagation in tunnels," IEEE Antennas and Propagation Magazine, vol. 49, no. 2, pp. 11-26, 2007.

[23] J. M. Molina-Garcia-Pardo, M. Lienard, A. Nasr, and P. Degauque, "On the possibility of interpreting field variations and polarization in arched tunnels using a model for propagation in rectangular or circular tunnels," IEEE Transactions on Antennas and Propagation, vol. 56, no. 4, pp. 1206-1211, 2008.

[24] X. Zhang and C. D. Sarris, "Vector parabolic equation-based derivation of rectangular waveguide surrogate models of arched tunnels," IEEE Transactions on Antennas and Propagation, vol. 66, no. 3, pp. 1392-1403, 2018.

[25] Z. Sun and I. Akyildiz, "Channel modeling and analysis for wireless networks in underground mines and road tunnels," IEEE Transactions on Communications, vol. 58, no. 6, pp. 1758-1768, 2010.

[26] F. Fuschini and G. Falciasecca, "A mixed rays-modes approach to the propagation in real road and railway tunnels," IEEE Transactions on Antennas and Propagation, vol. 60, no. 2, pp. 1095-1105, 2012.

[27] A. Ranjan, H. B. Sahu, and P. Misra, "Modeling and measurements for wireless communication networks in underground mine environments," Measurement, vol. 14912 pages, 2020.

[28] K. Laakman and W. Steier, "Waveguides: characteristics modes of hollow rectangular dielectric waveguides," Applied Optics, vol. 15, no. 5, pp. 1334-1340, 1976.

[29] A. R. Silva and M. C. Vuran, "Development of a testbed for wireless underground sensor networks," EURASIP Journal on Wireless Communications and Networking, vol. 2010, Article ID 620307, 14 pages, 2010.

[30] A. Ranjan, H. B. Sahu, and P. Misra, "MineSense: sensing the radio signal behavior in metal and non-metal underground mines," Wireless Networks, vol. 25, no. 6, pp. 3643-3655, 2019.

[31] M. D. Bedford, G. A. Kennedy, and P. J. Foster, "Radio transmission characteristics in tunnel environments," Mining Technology, vol. 126, no. 2, pp. 77-87, 2017. 